\title{
Role of Umbilical Artery Doppler in Predicting Intrauterine Growth Restriction and Foetal Outcome in Pregnant Ladies with Pregnancy Induced Hypertension
}

\author{
Sharma $\mathbf{P}^{1}$, Gyawali $\mathbf{M}^{1}$, Gurung SD ${ }^{2}$ \\ ${ }^{1}$ Department of Radiology and Imaging, Manipal Teaching, Hospital, Pokhara, Nepal \\ ${ }^{2}$ Department of Obstetric and Gynaecology, Manipal Teaching Hospital, Pokhara
}

Received: December 5, 2015

Accepted: March 04, 2016

Cite this paper:

Sharma P, Gyawali M, Gurung SD. Role of umbilical artery Doppler in predicting intrauterine growth restriction and foetal outcome in pregnant ladies with pregnancy induced hypertension. Nepalese Journal of Radiology 2017;7(10):3-8.

\begin{abstract}
Introduction: Umbilical artery doppler is a noninvasive tool in the evaluation of the foetal and uteroplacental circulation. The aim of this study was to evaluate the role of umbilical artery doppler in pregnancy induced hypertension $(\mathrm{PIH})$ ladies with clinical suspicion of intrauterine growth restriction (IUGR) and to predict the foetal outcome.
\end{abstract}

Methods: A total of 44 singleton pregnancies beyond 34 weeks of pregnancy complicated with pregnancy induced hypertension and clinical suspicion of intrauterine growth restriction were evaluated using ultrasonography and Doppler. Six pregnant ladies were excluded from the study. The umbilical artery systolic/diastolic (S/D) ratio was calculated from a free loop of cord midway between the placenta and insertion of cord. All the pregnant ladies were followed up till delivery. Birth weight, adverse foetal outcome were recorded. Babies were divided into two groups, small for gestational age (SGA) and appropriate for gestational age (AGA) based on Lubchenco growth chart. SGA was considered as IUGR.

Results: Abnormal S/D in umbilical artery was seen in 26 pregnant ladies, out of which 22 had an abnormal resistive index (RI). Umbilical artery S/D ratio had a sensitivity of $66.7 \%$ and specificity of $28.57 \%$, in diagnosing IUGR. Umbilical artery RI had a sensitivity of $50 \%$ and specificity of $28.6 \%$ in diagnosing IUGR. Similarly, S/D ratio of the umbilical artery had a sensitivity of $100 \%$, specificity of $46.2 \%$, in diagnosing adverse foetal outcome. RI was $100 \%$ sensitive in diagnosing foetal outcome.

Conclusion: Umbilical artery doppler plays an important role in PIH in diagnosing IUGR and predicting a foetal outcome.

Keywords: Doppler, IUGR, PIH, Umbilical Artery

Correspondence to: Dr. Prakash Sharma

Department of Radiology and Imaging,

Manipal Teaching Hospital

Email: prakashsharm@yahoo.com

Licensed under CC BY 4.0 International License which permits use, distribution and reproduction in any medium, provided the original work is properly cited 


\section{INTRODUCTION}

Hypertensive disorder during pregnancy is one of the most common complications that effect human pregnancy. It is one of the leading causes of maternal and foetal mortality \& morbidity. ${ }^{1}$ Intrauterine growth restriction (IUGR) is defined as those foetuses with birth weight less than the $10^{\text {th }}$ percentile for the gestational age. It is a significant condition associated with increased perinatal complications and neonatal death. Pregnancy induced hypertension (PIH) is a major complication affecting pregnancy which is associated with significant maternal and foetal complications. ${ }^{1}$ When both of these conditions are coexistent chances of complication is often increased. With the introduction of doppler to obstetrics, it has been possible to assess the foetal and uteroplacental circulation in a noninvasive way. Early diagnosis of intrauterine growth restriction helps in reducing perinatal and neonatal complication, mortality and morbidity. Doppler blood flow studies of umbilical artery are a better predictor of neonatal outcome than estimated foetal weight. ${ }^{2,3}$ As compared to uterine artery, umbilical artery is regarded as a good predicator of foetal outcome. ${ }^{4}$

There are scanty reports on the role of doppler in IUGR. Hence, the purpose of this study was to evaluate the role of umbilical artery doppler in PIH ladies with clinical suspicion of IUGR and to predict the foetal outcome.

\section{METHODS}

This prospective study was conducted in the Department of Radiology and Imaging between January 2014 and June 2015. Ethical clearance was obtained from the institutional review board.

Atotal of 44 singleton pregnancies complicated with PIH and clinical suspicion of IUGR were evaluated using ultrasonography and doppler. Pregnant ladies beyond 34 weeks of pregnancy were included in the study. Gestational age was calculated based on last menstrual period (LMP). Multifoetal pregnancies, Gestational diabetes, pregnant ladies who lacked follow up, ladies with uncertain LMP and chronic illness were excluded from the study. The detailed obstetric examination was performed followed by doppler of an umbilical artery using LOGIQ P3- GE Medical systems with 3.5 MHz curvilinear probe after obtaining a detailed history. The umbilical artery S/D ratio was calculated from a free loop of cord midway between the placenta and insertion of cord. Measurements were taken during foetal inactivity and apnea. All the pregnant ladies were followed up till delivery. Birth weight and adverse foetal outcome were recorded. Babies were divided into two groups as Small for gestational age (SGA) and Appropriate for gestational age (AGA) based on Lubchenco chart. SGA was taken as IUGR. Foetal outcome was recorded as normal and adverse outcome. The adverse outcome included perinatal hypoxia, periventricular leukomalacia, intraventricular haemorrhage, neonatal death. Out of 44 pregnant ladies, 1 was excluded due to chronic illness, 1 was excluded because of multifoetal pregnancy, 2 were lost during follow up and 2 were excluded because of uncertain LMP and gestational age. A total of 38 pregnant ladies were included for statistical analysis.

SPSS version 18 was used for statistical analysis. Sensitivity and specificity of S/D ratio in diagnosing IUGR and predicting foetal outcome were calculated. S/D ratio of $>3$ in umbilical artery was considered abnormal as per the standard reference value. Absent and reverse end diastolic flow was also considered abnormal. RI of umbilical artery $>0.7$ was considered as abnormal. ${ }^{4}$

\section{RESULTS}

A total of 38 pregnant ladies with $\mathrm{PIH}$ and clinical suspicion of IUGR beyond 34 weeks of gestation were included in the study. Age of 
the patients ranged from 20 to 30 years with mean age of $25.2 \pm 2.6$ years. Most of them were primigravida (52.6\%). Bad Obstetric history was present in 10/38 pregnant ladies $(26.3 \%)$. Most of the ladies had the amniotic fluid index (AFI) of 8 to $24 \mathrm{~cm}$ (Table 1).

Table 1: Amniotic fluid index of the pregnant ladies

\begin{tabular}{|c|c|c|}
\hline AFI & Frequency & Percentage \\
\hline$<5 \mathrm{~cm}$ & 4 & $10.5 \%$ \\
\hline 5 to $<8$ & 16 & $42.1 \%$ \\
\hline 8 to $<24$ & 18 & $47.4 \%$ \\
\hline
\end{tabular}

Out of 38 ladies, $30(78.9 \%)$ had lower segment caesarean section which was either elective or emergency. Abnormal S/D ratio in umbilical artery was seen in 26 pregnant ladies, out of which 22 had abnormal RI. Out of 38 foetuses, 24 had intrauterine growth restriction and 14 were appropriate for gestation. Adverse outcome was seen in 12 foetuses, out of which 5 had neonatal death. Both RI and S/D ratio of umbilical artery were abnormal in foetuses with adverse outcome. Umbilical artery S/D ratio had a sensitivity of $66.7 \%$, specificity of $28.57 \%$, the positive predictive value of $61 \%$ and negative predictive value of $33.3 \%$ in diagnosing IUGR (Table 2).

Umbilical artery RI had a sensitivity of $50 \%$, specificity of $28.6 \%$, positive predictive value of $54.5 \%$ and negative predictive value of $25 \%$ in diagnosing IUGR (Table 3 ).

Similarly, S/D ratio of umbilical artery had a sensitivity of $100 \% \%$, specificity of $46.2 \%$, positive predictive value of $46 \%$ and negative predictive value of $100 \%$ in diagnosing adverse foetal outcome (Table 4).

The sensitivity of umbilical artery RI in diagnosing foetal outcome was $100 \%$, specificity was $61.5 \%$, positive predictive value was $54.5 \%$ and negative predictive value was $100 \%$ (Table 5).

There were 4 pregnant ladies with eclampsia and 2 had HELLP syndrome.

There was no reversal of diastolic flow in umbilical artery. Three pregnant ladies had absent diastolic flow in umbilical artery. All three babies born to such mothers had prolonged NICU admission.

Table 2: Association between umbilical artery $S / D$ ratio and Lubchenco growth chart

\begin{tabular}{|c|c|c|c|}
\hline \multirow{2}{*}{$\begin{array}{l}\text { Umbilical artery } \\
\text { S/D ratio }\end{array}$} & \multicolumn{2}{|c|}{ Lubchenco growth Chart } & \multirow{2}{*}{ Total } \\
\hline & Small for Gestational age & Appropriate for gestational age & \\
\hline Abnormal & $16(66.7 \%)$ & $10(71.4 \%)$ & $26(68.4 \%)$ \\
\hline Normal & $8(33.3 \%)$ & $4(28.6 \%)$ & $12(31.6 \%)$ \\
\hline Total & $24(100 \%)$ & $14(100 \%)$ & $38(100 \%)$ \\
\hline
\end{tabular}

Table 3: Association between umbilical artery RI and Lubchenco growth chart

\begin{tabular}{|l|c|c|c|}
\multirow{2}{*}{$\begin{array}{c}\text { Umbilical artery } \\
\text { RI }\end{array}$} & \multicolumn{2}{c|}{ Lubchenco growth chart } & \multirow{2}{*}{ Total } \\
\cline { 2 - 3 } & Small for Gestational age & Appropriate for gestational age & \\
\hline Abnormal & $12(50 \%)$ & $10(71.4 \%)$ & $22(57.9 \%)$ \\
\hline Normal & $1250 \%)$ & $4(28.6 \%)$ & $16(42.1 \%)$ \\
\hline Total & $\mathbf{2 4 ( 1 0 0 \% )}$ & $\mathbf{1 4 ( 1 0 0 \% )}$ & $\mathbf{3 8 ( 1 0 0 \% )}$ \\
\hline
\end{tabular}


Table 4: Association between umbilical artery $S / D$ ratio and foetal outcome

\begin{tabular}{|l|c|c|c|}
\multirow{2}{*}{$\begin{array}{c}\text { Umbilical artery } \\
\text { S/D ratio }\end{array}$} & \multicolumn{2}{c|}{ Foetal Outcome } & \multirow{2}{*}{ Total } \\
\cline { 2 - 3 } & Adverse Outcome & Normal Foetus & \\
\hline Abnormal & $12(100 \%)$ & $14(53.8 \%)$ & $26(68.4 \%)$ \\
\hline Normal & $0(0 \%)$ & $12(46.2 \%)$ & $15(31.6 \%)$ \\
\hline Total & $\mathbf{1 2}(\mathbf{1 0 0} \%)$ & $\mathbf{2 6}(\mathbf{1 0 0} \%)$ & $\mathbf{3 8 ( 1 0 0 \% )}$ \\
\hline
\end{tabular}

Table 5: Association between umbilical artery RI and foetal outcome

\begin{tabular}{|l|c|c|c|}
\multirow{2}{*}{\begin{tabular}{c}
\multirow{2}{*}{ Umbilical artery } \\
RI
\end{tabular}} & \multicolumn{2}{c|}{ Foetal Outcome } & \multirow{2}{*}{ Total } \\
\cline { 2 - 3 } & Adverse Outcome & Normal Foetus & \\
\hline Abnormal & $12(100 \%)$ & $10(38.5 \%)$ & $22(57.9 \%)$ \\
\hline Normal & $0(0 \%)$ & $16(61.5 \%)$ & $16(42.1 \%)$ \\
\hline Total & $\mathbf{1 2 ( 1 0 0 \% )}$ & $\mathbf{2 6}(\mathbf{1 0 0} \%)$ & $\mathbf{3 8 ( 1 0 0 \% )}$ \\
\hline
\end{tabular}

\section{DISCUSSION}

Pregnancy induced hypertension (PIH) and small for gestational age result in improper flow of blood in uterine \& umbilical arteries. ${ }^{4}$ The purpose of prenatal examinations is to identify foetuses at increased risk for perinatal morbidity and mortality. Haemodynamic changes in the foetoplacental circulation are illustrated by umbilical artery velocimetry. As the number of tertiary stem villi and arterial channels increases, foetoplacental compartment develops, hence the impedance of the umbilical artery decreases. The resistance of Umbilical artery declines from 15 weeks of gestation. The diastolic component in the umbilical artery waveform appears during early second trimester. ${ }^{5}$

Yoon et al demonstrated that absent umbilical artery waveform is strongly associated with adverse perinatal outcome. ${ }^{6}$ Burrell SJ and colleague have found the positive role of umbilical artery doppler ultrasonography in reduction of perinatal mortality in highrisk pregnancies. ${ }^{7}$ Later, the finding was also confirmed by Westergaard $\mathrm{HB}$ et al. ${ }^{3}$

In a study conducted by Khalid $\mathrm{M}$ et al, out of 36 hypertensive patients, $80 \%$ had abnormal umbilical artery doppler study. ${ }^{8}$ In our study, out of 38 hypertensive patients, around $68 \%$ had abnormal umbilical artery doppler. Bhatt CJ et al found that $46 \%$ of hypertensive patients had abnormal umbilical artery doppler with abnormal S/D ratio. ${ }^{4}$

Age of our patients ranged from 20 to 30 years with mean age of $25.2 \pm 2.6$ years, which was similar to the study of Jasovic-Siveska E et al. $^{9}$ Around $53 \%$ of our patients were primigravida which was similar to the study of Khalid M et al. ${ }^{8}$

In our study, $63 \%$ were SGA and $37 \%$ were AGA, which was similar to the finding of Fleschier et.al. ${ }^{10} \mathrm{~A}$ reverse finding was observed by Khalid $\mathrm{M}$ et al, around $31 \%$ had SGA, 67\% had AGA and $2.78 \%$ had IUD. ${ }^{8}$ Around $13 \%$ of our patients had neonatal death.

In our study, abnormal $\mathrm{S} / \mathrm{D}$ ratio in umbilical artery was seen in $68 \%$ of pregnant hypertensive ladies and around $62 \%$ of those cases had IUGR babies almost similar to the finding of Bhatt $\mathrm{CJ}$ et $\mathrm{al} .{ }^{4}$ Khalid $\mathrm{M}$ et al found that $38 \%$ of hypertensive patients with abnormal umbilical doppler had IUGR babies. ${ }^{8}$ In our study around $55 \%$ of hypertensive pregnant ladies with abnormal umbilical artery RI and $62 \%$ of hypertensive pregnant ladies with abnormal S/D ratio had IUGR babies. 
A systematic review and bivariate metaanalysis has concluded that foetal umbilical artery doppler is a moderately useful test to predict mortality in a high-risk pregnancy population. ${ }^{11}$ In cases of IUGR, the presence of abnormal umbilical artery doppler is regarded as the best predictor of adverse perinatal outcome. $^{12}$ Lakhkar $\mathrm{BN}$ and colleagues observed that S/D ratio of Umbilical artery was the most sensitive in predicting perinatal morbidity but had a low specificity, sensitivity was $67 \%$ and specificity was $45 \% .{ }^{13}$ Ozeren M et al observed higher sensitivity of $88 \% .{ }^{14} \mathrm{We}$ had even higher sensitivity of abnormal S/D ratio of umbilical artery (100\%) in diagnosing adverse foetal outcome but specificity was only $46 \%$. In our study, adverse outcome was seen in $32 \%$ of cases, out of which $42 \%$ had neonatal death. Both RI and S/D ratio of umbilical artery were abnormal in foetuses with adverse outcome. Around 46\% of patients with abnormal S/D ratio had adverse foetal outcome whereas up to $55 \%$ of patients with abnormal RI had adverse foetal outcome.

\section{CONCLUSION}

Umbilical artery Doppler is an effective tool in diagnosing small for gestational age and predicting adverse foetal outcome. It should be routinely used in high risk pregnancies so that timely action can be taken for better outcome of foetus and mother. However, a study on larger sample size is recommended to generalize our finding.

\section{CONFLICT OF INTEREST}

None

\section{SOURCES OF FUNDING}

None

\section{REFERENCES}

1. Zeeman GG, Dekkor GA. Pathogenesis of preeclampsia: a hypothesis. Clin Obstet Gynecol 1992; 35:317-337. https://doi.org/10.1097/00003081 199235020-00014

2. Ott WJ. Intrauterine growth restriction and Doppler ultrasonography. $J$ Ultrasound Med 2000; 19(10):661-665. https://doi.org/10.7863/ jum.2000.19.10.661

3. Westergaard HB, Langhoff-Roos J, Lingman G, Marsál K, Kreiner S. A critical appraisal of the use of umbilical artery Doppler ultrasound in high-risk pregnancies: use of meta-analyses in evidence-based obstetrics. Ultrasound Obstet Gynecol 2001; 17(6):466-476. https://doi.org/10.1046/j.1469$\underline{0705.2001 .00415 . x}$

4. Bhatt CJ, Arora J, Shah MS. Role of color doppler in pregnancy induced hypertension(a study of 100 cases). Indian $J$ Radiol Imaging 2003;13:417-420. Available from: http://www.ijri. org/text.asp?2003/13/4/417/28724 [Accessed 5th November 2015].

5. Schulman H, Gleischer A, Stern W, et al. Umbilicalwaveratiosinhumanpregnancy. Am J. Obstet Gynecol 1984; 148:985-990. https://doi.org/10.1016/0002$\underline{\text { 9378(84)90541-6 }}$

6. Yoon Bh, Lee CM, Kim SW. An abnormal umbilical artery waveform; a strong and independent predictor of adverse perinatal outcome in patients with pre eclampsia Am J Obstet Gynecol 1994; 171:713-721. https://doi.org/10.1016/0002$\underline{\text { 9378(94)90087-6 }}$

7. Burrell SJ, Kingdom JC. The use of umbilical artery Doppler ultrasonography in modern obstetrics.CurrOpinObstet Gynecol. 1997; 9(6):370-374. https://doi.org/10.1097/00001703199712000-00007 
8. Khalid M, Shagufta S, Kumar V, et al. Doppler Indices in Prediction of Foetal Outcome in Hypertensive Pregnant Women. Nepal Journal of obstetrics and gyncecology 2011;6(11):28-34 . https://doi.org/10.3126/njog.v6i1.5249

9. Jasovic-Siveska E, Jasovic V, Stoilova S. Previous pregnancy history, parity, maternal age and risk of pregnancy induced hypertension..Bratisl Lek Listy 2011; 112(4):188-191. Available from: http://bmj.fmed. uniba.sk/2011/11204-07.pdf [Accessed 6 th November 2015].

10. Fleischer A, Schulman H, Farmakides G, et al. Uterine artery doppler primary in pregnant women with hypertension. Am J Obstet Gynecol 1986; 154:806-813. https://doi.org/10.1016/00029378(86)90462-X

11. Morris RK, Malin G, Robson SC, et al. Foetal umbilical artery Doppler to predict compromise of foetal/ neonatal wellbeing in a high-risk population: systematic review and bivariate meta-analysis. Ultrasound Obstet Gynecol 2011; 37(2):135-142. https://doi.org/10.1002/uog.7767

12. Gonzalez JM, Stamilio DM, Ural S, et al. Relationship between abnormal foetal testing and adverse perinatal outcomes in intrauterine growth restriction. $\mathrm{Am}$ J Obstet Gynecol 2007; 196(5):48-51. https://doi.org/10.1016/j. ajog.2007.01.010

13. Lakhkar BN, Rajagopal KV, Gourisankar PT.Dopplerprediction ofadverseperinatal outcome in PIH and IUGR. Indian $J$ Radiol Imaging 2006; 16:109-116. https://doi.org/10.4103/0971 $\underline{3026.29064}$
14. Ozeren M, Dinç $H$, Ekmen U, et al. Umbilical and middle cerebral artery Doppler indices in patients with preeclampsia. Eur $J$ Obstet Gynecol Reprod Biol 1999; 82(1):11-16. https://doi.org/10.1016/S03012115(98)00167-5. 